\title{
Pastoralist Perceptions on Climate Change and Variability in Kajiado in Relation to Meteorology Evidence
}

Bobadoye A.0

PhD scholar Institute for climate change and adaptation, University of Nairobi

Professor Ogara W.O

Lecturer Institute for climate change and adaptation, University of Nairobi

Dr. Ouma, G.O

Lecturer Institute for climate change and adaptation, University of Nairobi

Dr. Onono, J.O

Lecturer Institute for climate change and adaptation, University of Nairobi Email of corresponding author: bobadoyed@gmail.com

\section{Doi:10.5901/ajis.2016.v5n1p37}

\section{Abstract}

This study provides an overview of changing climatic conditions in Kajiado County based on analysis of climatic data and perception of pastoralist on key climatic variables. It collates the two sources of knowledge on climate change, indicating the consistency and inconsistency between the two. Rainfall and temperature data of the study area for a period of 43 years (1970-2013) was collected from Kenya Meteorological Service, organized and analyzed using Microsoft excel. The perception of Maasai pastoralist to climate change was determined using questionnaires, focus group discussions and key informant interview. Result shows that rainfall trend in Kajiado County have a high variability level (CV \%) of 27.5\% for Kajiado North, 21.5\% for Kajiado West, $26.4 \%$ for Kajiado East and 25.2\% for Kajiado Central. Although, there is no significant change for rainfall over the study period, result on perception revealed that $83 \%$ of respondent perceive that rainfall amount is reducing in the last 30years. However, perception of pastoralist about years of extreme drought corroborates the meteorological trend of years with very low rainfall. A rise in minimum temperature $\left(1.41{ }^{\circ} \mathrm{C}\right)$, maximum temperature $(0.470 \mathrm{C})$ and average temperature $\left(0.94^{\circ} \mathrm{C}\right)$ occurred between 1970 and 2013 . This agrees with the perception of $81 \%$ of Maasai pastoralist, which perceived that temperature has been increasing in the last 30 years. Overall, the results of this study are in line with recent trend of global warming in the region as reported by the latest Intergovernmental panel on Climate Change (IPCC 2014) report.

Keywords: climate change, rainfall, temperature, perception

\section{Introduction}

Climate change is a hot global issue that is gaining momentum throughout the world and Kenya is not left out. Several studies have been conducted on understanding climate change and variability. Most of these studies are focused on analysis of meteorological records for identifying climate trends and forecasting future climatic trends. However, it has also been realized that these data based trend analysis and climate change projections are unable to capture the microlevel changes and impacts of climate change (IPCC, 2007). Rebetez (1996) stressed the difficulties in receiving and making use of scientific information in decision-making process by policy makers, local communities and media personnel. Interpreting such climatic analysis to local communities who feels the direct effect of climate change can also be challenging.

Arid and semiarid lands (ASALs) are particularly vulnerable to climate change due to the dominance of pastoralism and rain-fed agricultural food production system. If the condition continues as they are, the impacts of increased temperature from global warming and variable precipitation resulting from climate change and variability will further depress marginal lands in the ASAL regions of Kenya. The ASALs constitute about 80 percent of the total land surface 
area in Kenya (Nyariki, 2002; Anwata, 2013) and account for about 30 percent of the total national population and 50 percent of the total livestock population and vast amount of untapped natural resources (ROK, 2004; UNDP, 2010).

Comparing meteorological data with people's perception of climate change is important in planning adaptation options with the community. Ban and Hawkins (2000) define perception as the process by which we receive information or stimuli from our environment and transform it into psychological awareness. Deressa et al. (2009) reported that for households to decide whether to adapt or not to climate change and variability, they must first perceive the change. Studies by Amwata, (2013) shows that ASAL communities in Kenya are mainly dominated by pastoralist who are vulnerable to climate change and variability due to their dependence on climate sensitive livelihood activities. It is therefore important to understand the perception of ASAL communities to climate parameters and relate their perception with meteorological data. Studies on perception, awareness and local knowledge at the household and community levels can provide the basis for concepts and methods for assessing climate change vulnerability and adaptation strategies of the livelihood of the pastoralist communities. Planning adaptation strategies to climate change requires adequate understanding of climate parameters by all stakeholders including researchers, pastoralist communities, policy makers, extension agents and the private sector.

The objective of this study is to analyze the trend of climate parameters (rainfall and temperature) in Kajiado County and compared it with the perception of Maasai pastoralist on climate change and variability. This analysis will be useful for the government and policy makers for climate change adaptation planning in Kajiado County.

\section{Materials and Methods}

\subsection{Study area}

The study was carried out in selected villages in Kajiado County in Kenya. Kajiado County is located in the southern tip of the former Rift valley province between longitudes 3605 and 3705 and latitudes $1^{\circ} 0$ and $3^{\circ} 0$ South (Amwata, 2013). It covers an area of $19,600 \mathrm{Km}^{2}$ (CBS, 1981). The County has 173,464 households, a population of 687,312 , and $50.2 \%$ are male; $49.8 \%$ are female. Kajiado County borders Tanzania to the south, Taita Taveta County to the west, Narok County to the east and Nakuru, Kiamnau, Nairobi and Makueni Counties to the north.

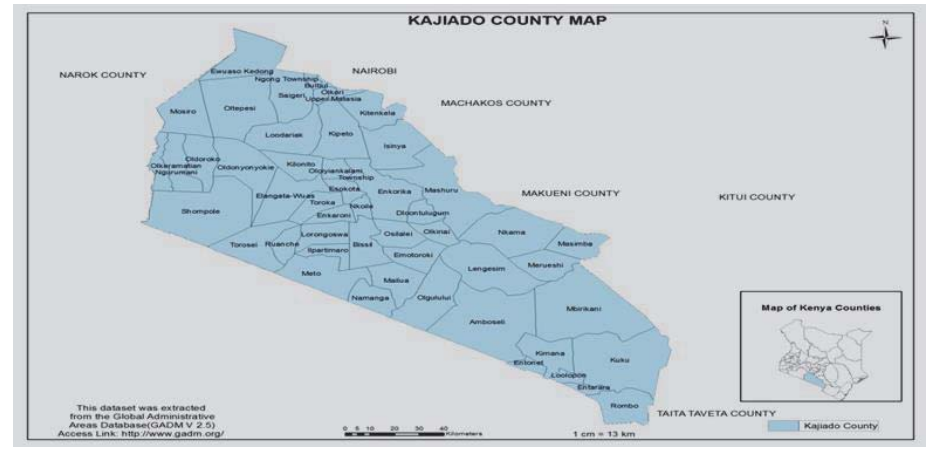

Figure 1: Map of Kajiado County

\subsection{Perception of Maasai pastoralist to climate change and variability}

The perception of Maasai pastoralist to climate change was accessed using semi structured questionnaire and key informant interview. The field study was conducted in the five administrative wards in Kajiado East sub-county (Oloosirkon/Sholinke, Kitengela, Kapetui North, Kenyawa-Poka and IImaroro). The multistage sampling technique was used in this study. Kajiado East sub-county was purposively sampled based on the geographical location, dominant livelihood activities and accessibility. Two hundred and fifty (250) household questionnaires were administered and 30 key informant interviews conducted between October 2014 and January 2015. 


\subsection{Data collection}

A semi-structured questionnaire was used for data collection. Information on perception of Maasai pastoralist to climate change and variability was obtained through the administration of the questionnaires on household heads. To avoid misinterpretation, the research assistants conducted the household interviews in the local language. The study also conducted twenty (30) personal interviews mostly with Maasai women and youth, government officials and representatives of various interest groups that have been working on drought managements in the study area. The interviews created opportunity for in-depth interaction between the different stakeholders and the researcher. It also further reveals the communities local knowledge and perception about climate change and variability. Rainfall data from four different stations in Kajiado County were sourced from the Kenya Meteorological service (KMS) and used for this analysis. Average monthly rainfall were collected from Ngong forest station in Kajiado north area located at $1.31^{\circ} \mathrm{S}$, $36.65^{\circ} \mathrm{N}$, Mashuru meteorological station in Kajiado central area with located at 2.10 ${ }^{\circ} \mathrm{S}, 37.10^{\circ} \mathrm{E}$, Magadi soda works in Kajiado west, located at $1.88^{\circ} \mathrm{S}, 36.28^{\circ} \mathrm{E}$ and Maasai rural trading centre Isinya in Kajiado east, located at $1.40^{\circ} \mathrm{S}$, $36.50^{\circ} \mathrm{E}$. The rainfall data were analyzed for a period of 43 years $(1970-2013)$. The stations were selected because of the availability of long-term data and their presence within the different sub-counties in Kajiado County. Average monthly temperature for Kajiado was also collected from KMS and analyzed for the study.

\subsection{Data Analysis}

Analysis of data combined both qualitative and quantitative approaches. Microsoft excel was used for the rainfall and temperature trend analysis and for graphical representation and the co-efficient of variation calculation. Climate variability factors such as years of successive poor rainfall, below normal rainfall and heavy rainfall were also presented in graphical forms. Data collected on perception to climate change was coded and analyzed using Microsoft excel. Descriptive statistics were used to provide insight into perception of Maasai pastoralist to climate change.

\subsection{Standardized Precipitation Index (SPI)}

The standardized precipitation index (SPI) was used to analyze drought severity in the study area between 1970 and 2013. SPI is a method that designed to quantify precipitation deficit for multiple time scale (McKee et al., 1993). The SPI in this study was calculated for four meteorological stations in Kajiado County. The SPI was calculated by dividing the difference between normalized seasonal precipitation and its long-term seasonal mean by standard deviation as follows:

$\mathrm{SPI}=\underline{X i j-X i m}$

$S D$

Where $X i j=$ Seasonal precipitation value at jth station

$X i m=$ Long term seasonal mean precipitation

$S D=$ Standard deviation

Table 1: SPI classification used in this study

\begin{tabular}{cl}
\hline SPI values & Classification \\
\hline 2.0 & Extremely wet \\
1.5 to 1.99 & Very wet \\
1.0 to 1.49 & Moderately wet \\
-.99 to .99 & Near normal \\
-1.0 to -1.49 & Moderately dry \\
-1.5 to -1.99 & Severely dry \\
-2 and less & Extremely dry \\
\hline
\end{tabular}

\section{Results and Discussion}

\subsection{Meteorological rainfall trend and pastoralist perception of rainfall in Kajiado County}

The annual rainfall trend for the four meteorological stations in (Kajiado east, north, central and west) from 1970-2013 is presented in Figure 2. The rainfall trend in all the stations shows high level of inter-annual variation. Rainfall is becoming 
highly variable and unpredictable especially in recent decades and the year 2000 was recorded as the driest year by the meteorological stations. However table 2 shows that despite the high coefficient of variance (\% CV) of $27.5 \%$ for $\mathrm{Ngong}$, Kajiado North, 21.5\% for magadi Kajiado west, 26.4\% for Isinya Kajiado central and 25.2\% for Mashuuru Kajiado east, the inter-annual rainfall trend for the study area shows no significant difference $(P<0.05)$ between the year 1970 and 2013. This concurs with other research (Mutai and Ward 2000; Opole 2013; Opiyo 2014) conducted in similar ecosystem which reported that there is a high variation in rainfall pattern in ASALs of Kenya but such variation is not statistically significant in most areas.

The perception of Maasai on rainfall trends in the last 30 years (Figure 3) shows that $83 \%$ of Maasai pastoralist believed that amount of annual rainfall is reducing, $12 \%$ perceived that rainfall is becoming unpredictable; while only $5 \%$ reported that they do not know if rainfall is increasing over the last 30years. Focus group discussant agreed that increasing drought and dry spell is threatening pastoralist livelihood in Kajiado County. They agreed with one of them that:

Although Maasai are known worldwide as pastoralist, however, the rate at which drought and dry spell is increasing and also the continuous sales and fencing of land will most likely lead to the end of pastoralism in Kajiado County within the next 20 years.

Relating and comparing meteorological data with people's perception of climate parameters especially rainfall and drought has been a major contentious issue in climate change adaptation research (Opiyo, 2014). The perception of Maasai pastoralist about annual rainfall trend does not exactly agree with meteorological rainfall data collected for the study area. Although, inter annual coefficient of variation (CV\%) shows high level of variation in rainfall, the trend analysis shows there is no significant difference in the average amount of rainfall within the study period. Maasai pastoralist generally relate rainfall amount to its ability to sustain availability of pasture throughout the season. This indicates that even in seasons where there is no meteorological evidence of reduced annual rainfall, factors such as reduced rain days, and external factors such as land use change can affect the availability of pasture, and this to a Maasai pastoralist is a form of drought. It is therefore expedient for researchers and policy makers to understand the perception of Maasai pastoralist to climate change and the influence of other factors such as land use change on the pastoralist system when planning adaptation strategies in the ASALs in Kenya.
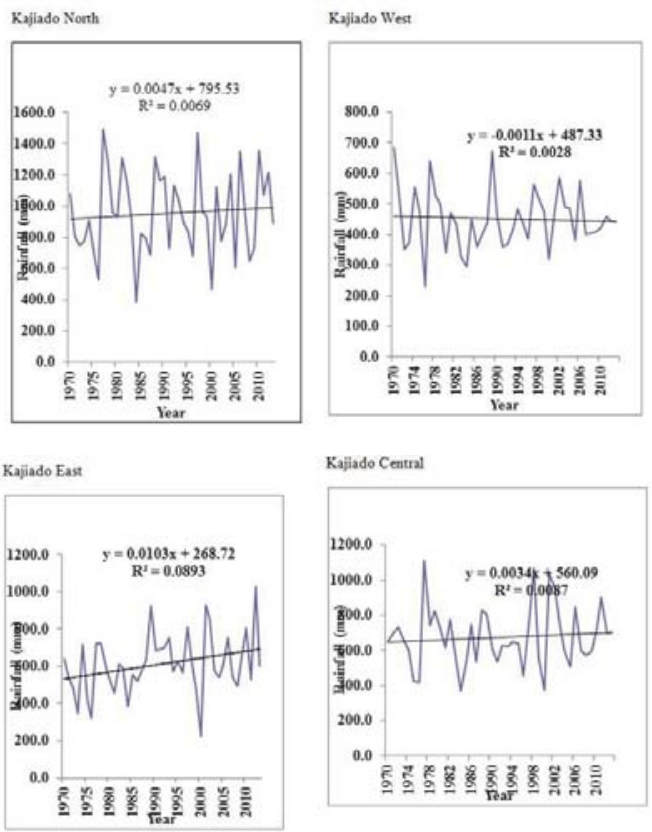

Figure 2: Rainfall trends in Kajiado County 
Table 2: Inter-Annual and spatial variability between four stations

\begin{tabular}{lcccc}
\hline & \multicolumn{4}{c}{ Station } \\
\cline { 2 - 5 } Statistic & Ngong MS (KN) & Magadi MS (KW) & Isinya MS (KE) & Mashuuru MS (KC) \\
\hline Mean(mm) & 979.2 & 450.6 & 612.2 & 674.5 \\
Standard Deviation & 268.4 & 96.8 & 161.3 & 171.7 \\
CV\% & 27.5 & 21.5 & 26.4 & 25.5 \\
P-value & 0.93 & 0.96 & 0.76 & 0.92 \\
\hline
\end{tabular}

Inter-annual rainfall data shows no significant rainfall trend ( $P>0.05)$ between 1970 and 2013.

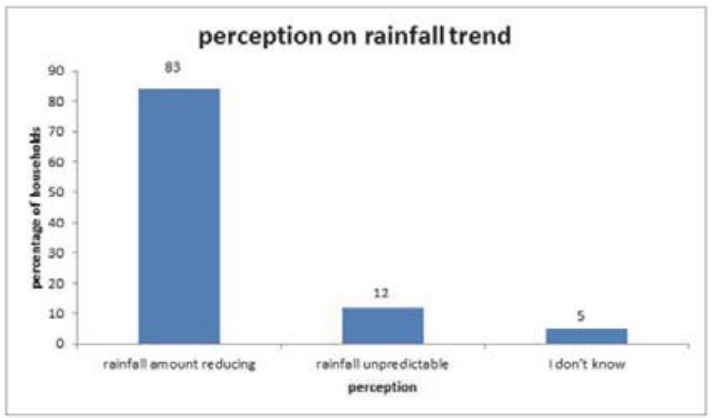

Figure 3: Maasai pastoralist perception on annual rainfall trend in Kajiado East in the last 30 years

\section{Annual Rainfall Anomalies and Perception of Drought by Maasai Pastoralist in Kajiado East}

Absence of a precise and universally accepted definition of drought can lead to some confusion on severity and interpretation to the community (Ellis et al., 1998). The various scientific definition of drought does not most time agree with the pastoralist definition of drought. Meteorological drought is defined solely based on the degree of dryness and duration of dry period and it must be region (FAO, 2013). Agricultural drought focuses on factors such as actual and potential evapo-transpiration and soil water deficiency; it occurs when there is insufficient soil moisture to meet the needs of a particular crop at a particular time. The Kenya Meteorological Service (KMS) defines normal meteorological drought as a situation when rainfall over an area is less than $75 \%$ of the climatological normal. However, field study shows that pastoralist define drought as a period of sustained insufficient pasture to feed the animals.

The result of rainfall anomalies in Kajiado County (Figure 4) calculated using standard precipitation index (SPI) shows wide variation in rainfall in the study area. The result shows that many years of low rainfall were experience in the study area between 1970 and 2013. Low annual rainfall was observed in 1973, 1975, 1981, 1984, 1999, 2000, 2004, 2007, 2008 and 2011 for all the stations observed in this study. This finding agrees with findings of Orindi et al., (2008); ICPAC (2007) and Amwata (2013) that in Kajiado drought phenomenon has occurred during the years 1973, 1975, 1980, 1984, 1994, 2000 and 2008. The result is also consistent with the findings of Opiyo (2014) who reported similar drought trend in arid and semi-arid lands of Kenya.

The perception of Masaai pastoralist about the number of years of extreme drought (Table 3) shows similar trend with the meteorological rainfall anomalies report. This shows that the Maasai pastoralist keep good record of climatic trends and events. Field study revealed that Maasai pastoralist recorded extreme drought in nine (9) years (2011, 2009, $2005,2000,1998,1994-1996,1990-1991,1984,1981,1980)$ between the year 1980 and 2013. This agrees with the chart on rainfall anomalies, which recorded extreme low rainfall for most of dry years observed by the Maasai pastoralist. Amwata (2014) also reported similar years of drought in a study conducted in ASALs of Kenya. The Findings of this study also corroborate previous observations by Hastenrath et al., (2011); Cook and Vizy (2013); Omondi et al., 2013 conducted in arid and semi-arid lands in eastern Africa. This finding shows the importance of indigenous knowledge in climate observation. It shows that rural dwellers especially farmers and pastoralist who depends on rainfall for livelihood sustenance have useful information on climatic trends and they should be actively involved in decision making in their communities. 


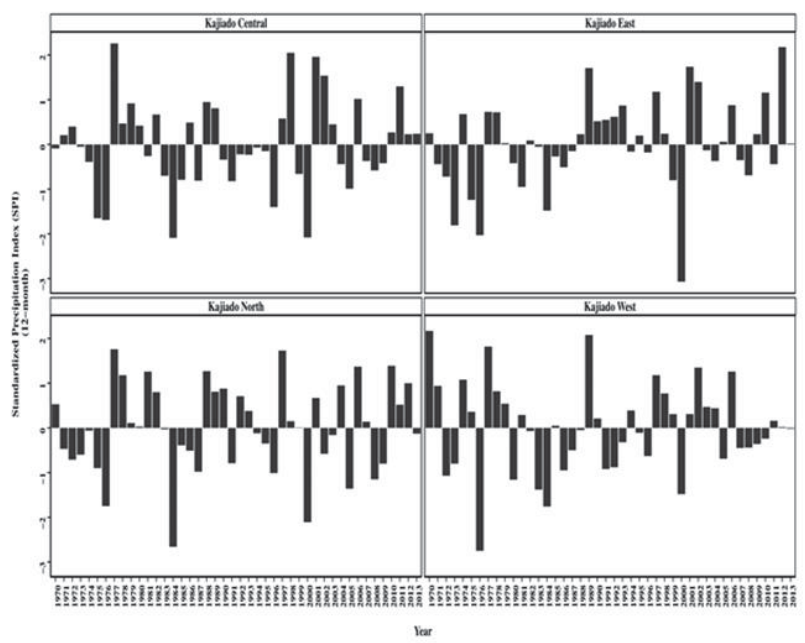

Figure 4. Annual rainfall anomalies in Kajiado East from 1970-2013

The perception of the level of risk of drought in the study area (figure 6 ) shows that $81.4 \%$ of the respondent agrees that drought is causing high risk to the pastoral economy in the study area, $16.4 \%$ perceive that drought is causing medium risk and 2.2\% perceive that drought is causing low risk in the study area. Several studies (Nkedianye et al., 2011; Nicholson 2014; Opiyo 2014) have reported the effect of increasing drought occurrence on the pastoral economy in the ASALS of Kenya. Drought poses' serious challenges to the pastoral economy, which account for 90 percent of employment opportunities and 95 percent of family incomes and livelihood security in ASALs of Kenya (ASAL Policy, 2012). According to Intergovernmental Panel on Climate Change (IPCC 2014) report, there is likely to be a marked increase in drought severity over much of Eastern Africa by 2050, this will threaten climate sensitive economy like agriculture and pastoralism in the region. This result confirms the high risk of drought in the ASALs of Kenya and further buttress the need for collaboration among stakeholders (government, researcher and the community) to develop coping and adaptation strategies to address climate change and its effect in the ASALs of Kenya.

Table 3: Perception of Maasai pastoralist on the years of extreme climate events in Kajiado East sub-County

\begin{tabular}{cll}
\hline Year & Events & Impact on people \\
\hline 2011 & Drought & Loss of animals and migration of animals to national park and loitokitok \\
2009 & Drought & Death of livestock and wild animals, People move their livestock as far as Tanzania \\
2005 & Drought and famine & Death of livestock and wildlife.lack of grains for human \\
2000 & Drought & Maasai were given yellow maize for food aid. Loss of animals \\
1998 & Heavy rains & Bumper harvest of maize, livestock suffered from bloat \\
$1994-1996$ & Drought & Livestock taken to Nairobi in search of pasture for the first time \\
$1990-1991$ & Drought & Not enough grazing for livestock, Maasai women started diversifying sources of income \\
1984 & Drought & East Coast fever (Oldikana) outbreak. Maasai were given yellow maize for the first time as food \\
1981 & Drought & aid. The drought was called the drought of the yellow maize \\
1980 & Drought & Loss of livestock and starvation of Maasai \\
\hline
\end{tabular}

Source: Field study 


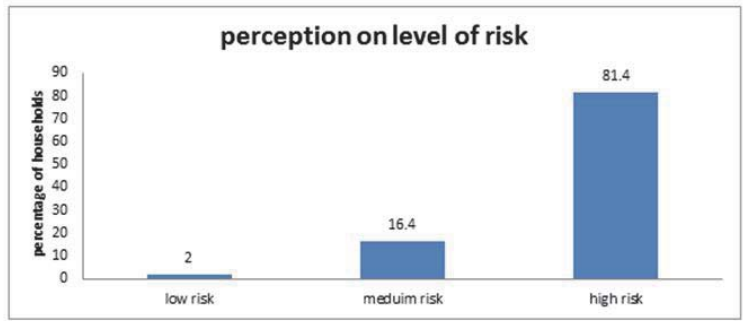

Figure 5. Maasai pastoralist perception on the level of risk of drought in Kajiado East sub-County

\section{Trend Analysis for Annual Temperature in Kajiado County and Perception of Maasai Pastoralist to Temperature Increase in Kajiado County}

Temperature trend was analyzed to provide a scenario of temperature variability in Kajiado County. The Result for temperature trend in Kajiado (Figure 6) shows an increasing temperature trend for average annual, average maximum temperature (Tmax) and average minimum temperature (Tmin). Overall, a rise in minimum $\left(1.41^{\circ} \mathrm{C}\right)$, maximum $\left(0.47{ }^{\circ} \mathrm{C}\right)$ and average $\left(0.94^{\circ} \mathrm{C}\right)$ was observed between the year 1970 and 2013 in the study area. This confirms the effect of global warming in Kajiado County. Kenya Meteorological Department (KMD) reported that the trend of minimum temperature from 1960 has been increasing by $0.8-2.0^{\circ} \mathrm{C}$, while the maximum temperature has been increasing by $0.1-0.7^{\circ} \mathrm{C}(\mathrm{GOK}$, 2010a). The study also agrees with the IPCC (2014) report that predicted an average temperature increase of $0.2^{\circ} \mathrm{C}$ per decade for Kenya. The results are consistent with previous results in the region by Opiyo, (2014); Anwata, (2013); King'uyu et al., (2000) which all reported increasing temperature over the years in arid and semi-arid lands of Kenya. Studies from Omondi et al., (2013) and Collins (2011) reported a general increasing warming temperature in ASALs in Kenya; they reported that the increasing temperature is particularly higher in the night and cold extreme in the night are decreasing in the horn of Africa region.

The report also shows that the years 2000, 1987, 2009, 1997 and 2011 recorded the highest annual temperature of $25.84,25.58,25.53,25.46$ and $25.43^{\circ} \mathrm{C}$ respectively. The years $1989,1978,1985,1974$ and 1979 had the lowest annual temperature of $23.92,24.08,24.21,24.35$ and $24.35^{\circ} \mathrm{C}$ respectively. This result generally shows a clear changing temperature pattern at the local level and confirms that global warming can be revealed even at the local scale. The result on average monthly temperature for Kajiado County shows that the month of March has the highest average monthly temperature of $\left(21.15^{\circ} \mathrm{C}\right)$ followed by February $\left(20.77^{\circ} \mathrm{C}\right)$ and April $\left(20.45^{\circ} \mathrm{C}\right)$ respectively. The months of July, August and June had the lowest temperatures of $17.18,17.49$ and $17.98^{\circ} \mathrm{C}$ respectively. The result is also consistent with Collins (2011) which indicates that rapid warm from 1979 onward is experienced in Kenya.

The meteorological trend of temperature recorded in this study is consistent with the perception of Maasai pastoralist about temperature change in the study area (Figure 7). The result on the perception of Maasai pastoralist on temperature change in the study area shows that $81 \%$ of the respondent perceived that average temperature is increasing while only $4 \%$ perceived that temperature is reducing. This shows that the Maasai pastoralists are already experiencing the effect of increased temperature on their livelihood. The study also agrees with the findings of Amwata (2013) which reported that farmers in arid and semi arid lands of Kenya already perceive the effect of change in temperature and rainfall, and that they are developing coping strategies to the adverse effect of climate change.
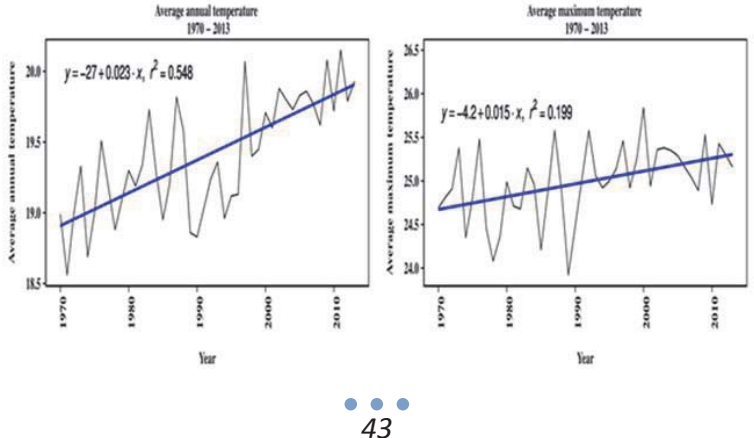

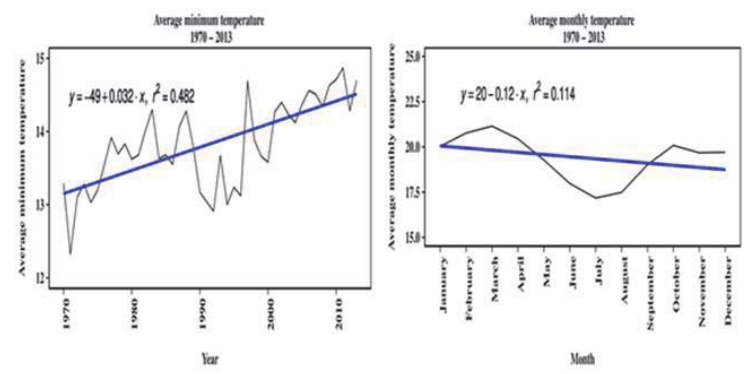

Figure 6: Trend analysis of temperature in Kajiado East from 1970-2013

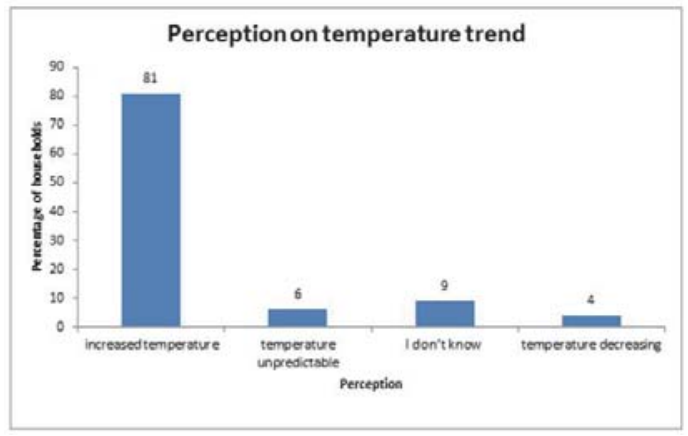

Figure 7: Perception of Maasai pastoralist on temperature change in Kajiado County in the last 30 years

\section{Conclusion and Recommendation}

Response to climate change and variability involves the development of effective adaptation strategies to minimize the effect and maximize the available opportunities. This is however based on robust information on the trend of climate parameters especially rainfall and temperature. Rural communities over the years have developed indigenous methods of predicting climate trends. They also have useful information about climatic trends and occurrence of extreme climatic events such as drought in their communities. It is therefore important to understand the perception of communities about climate change and variability in planning adaptation strategies. This study demonstrates how statistical analysis and people's perception can be used to characterize climate parameter (temperature and rainfall) trend at a local scale. The findings of this study will be useful for researchers and policy makers in management of the pastoral system in ASALs of Kenya.

This study recommends that both indigenous and scientific knowledge should be combined in understanding and presenting climatic information to the communities. The communities are very important stakeholders in adaptation planning and understanding their perception about climate change and variability is important in climate adaptation planning. In addition, more detailed climatic information such as number of rain days that determines the length of growing season is important in understanding climate trend and it's important on climate dependent livelihoods such as pastoralism. This study could not provide such information due unavailability of daily rainfall data by the meteorological department. Further study on the impact of changes in seasonal rain days on the pastoralist and agro pastoralist in ASALs of Kenya is therefore recommended by this study.

\section{References}

Amwata, D.A. (2013). The influence of climate variability and change on Land-use and Livelihoods in Kenya's Southern rangelands. A $\mathrm{PhD}$ thesis submitted to the Department of Land Resource Management and Agricultural Technology, University of Nairobi.

ASAL Policy (2012). National Policy for the Sustainable Development of Northern Kenya and other Arid Lands. 
Ban, A.W. Van den and H.S. Hawkins. (2000). Agricultural Extension, second edition, Blackwell Science, UK.

Collins, J. M. (2011). Temperature variability over Africa. Journal of Climate 24: 3649-3666.

Cook, K. H. and Vizy, E. K. (2013). Projected Changes in East African Rainy Seasons. Journal of Climate 26:16, 5931-5948.

Deressa, T.T., Hassan, R.M., Ringler, C., Alemu, T. and Yesuf, M.(2009). Determinants of farmers" choice of adaptation methods to climate change in the Nile Basin of Ethiopia. Global Environmental Change 19: 248-255.

Ellis, J.E. and Swift.D.M. (1988). Stability of African pastoral ecosystems: alternate paradigms and implications for development. Journal of Range Management 41: 450-459.

FAO (2013) Food security and agricultural mitigation in developing countries: options for capturing synergies. FAO, Rome.

Government of Kenya (GOK). 2010a. National climate change response strategy. Nairobi: Government Press.

Hastenrath, S., Polzin, D. and Mutai, C. (2011). Circulation Mechanisms of Kenya Rainfall Anomalies. Journal of Climate 24(2): 404-412.

IGAD Climate Prediction and Application Centre (ICPAC). (2007). Climate variability and change and human development in Africa: Assessing the risk and vulnerability of climate variability and change in Kenya, Malawi and Ethiopia. ICPAC, Nairobi, Kenya.

IPCC AR4 WG2 (2007). Parry M.L., Canziani, O.F., Palutikof, J.P., Van der Linden, P.J. and Hanson, C.E. ED. Impacts, Adaptation and Vulnerability.Contribution of the working group II to the Fourth Assessment Report of the Intergovernmental panel on Climate change, Cambridge University Press, ISBN 978-0-521-88010-7.

IPCC (2014). Climate change 2014. Impacts, Adaptation and Vulnerability. Contribution of working group II to the Fifth Assessment Report of the Intergovernmental panel on climate change.

King'uyu, S.M., Ogallo L.A. and Anyamba, E.K.(2000). Recent trends of minimum and maximum surface temperatures over Eastern Africa. Journal of Climate 13(16): 2876-2886.

Nyariki, D.M., Wiggins, S.L. and Imungi, J.K. (2002). Levels and causes of household food and nutrition insecurity in dryland Kenya. Ecology of Food and Nutrition, 41(2): 155-169.

Nkedianye, D., de Leeuw, J., Ogutu, J.O., Mohammed, Y. S., Terra L. S., Kifugo. S. C., Kaelo D. S. and Reid, R. S. (2011). Mobility and livestock mortality in communally used pastoral areas: the impact of the 2005-2006 droughts on livestock mortality in Maasailand. Pastoralism: Research, Policy and Practice 1:17.

Nicholson Sharon, E. (2014). A detailed look at the recent drought situation in the Greater Horn of Africa. Journal of Arid Environments 103: 71-79.

McKee, T.B., Doesken, N.J., and Kleist, J. (1993). The Relationship of Drought Frequency and Duration to Time Scales. Proceedings of the Eigth Conference on Applied Climatology, American Meteorological Sociey pp.179-184.

Mutai, C.C. and Ward, M.N. (2000). East African rainfall and the tropical circulation/convection on intra-seasonal to inter-annual timescales. Journal of Climate 13: 3915-3939.

Opiyo, E. O. (2014). Climate variability and change on vulnerability and adaptation among turukana pastoralist in north-western Kenya. A $\mathrm{PhD}$ thesis submitted to the Department of Rangeland management, University of Nairobi.

Opole, M.O. (2013). The impact of climate variability on pastoralism: Forage dynamics and trends of cattle population in Kajiado county, Kenya. A Research project submitted in partial fulfillment of the requirement of Masters in Arts Degree in Climatology in the Department of Geography and Environmental studies, University of Nairobi

Omondi, P., Ogallo, L.A., Anyah, R., Muthama, J.M. and Ininda, J. (2013). Linkages between global sea surface temperatures and decadal rainfall variability over Eastern Africa region. International Journal of Climatology 33: 2082-2104.

Orindi, V.A., Nyong, A. and Herrero, M. (2008).Pastoral Livelihood Adaptation to Drought and Institutional Intervention in Kenya.Human Development Report 2007/2008.

Rebetez, M., (1996).Public expectation as an element of human perception of climate change. Climate Change, 32, pp. 495-509. Kluwer Academic Publishers, The Netherlands.

Saarinen, T.F., 1976. Environmental planning: perception and behavior. Houghton Mifflin Comp. Boston

ROK (2004). National policy on sustainable development of the arid and semi arid lands of Kenya, Nairobi, Kenya.

United Nations Development Programme (UNDP) (2010). Kenya national disaster profile. Enhanced security Unit, UNDP, Nairobi, Kenya. www://mirror.undp.org/kenya 
